\title{
Brain banking in the twenty-first century: creative solutions and ongoing challenges
}

\author{
This article was published in the following Dove Press journal: \\ Journal of Biorepository Science for Applied Medicine \\ 13 August 2014 \\ Number of times this article has been viewed
}

\author{
Rivka Ravid' \\ Young Mok Park ${ }^{2,3}$ \\ 'Brain Bank Consultants, \\ Amsterdam, the Netherlands; \\ ${ }^{2}$ Division of Mass Spectrometry \\ Research, Korea Basic Science \\ Institute, Ochang, South Korea; \\ ${ }^{3}$ Center for Cognition and Sociality, \\ Institute for Basic Science, Daejeon, \\ Republic of Korea
}

\begin{abstract}
Brain-banking organizations that collect and supply clinically and neuropathologically well-documented tissue specimens are essential for high-quality research into neurological and psychiatric disorders. The growing number of sophisticated neurobiological techniques that can be applied to human specimens obtained from donors at autopsy has increased the pressure on brain banks (BBs) to provide tissue for research conducted within the scientific community and pharmaceutical companies. A number of active BBs have been established worldwide in the past decade, and form an important link between tissue donors, their relatives, clinicians, neuropathologists, and scientists. There are established rapid-autopsy systems in various countries, based on local donor programs. These facilitate collection of tissue specimens, with the informed consent of donors with neurological and/or psychiatric disorders, and from controls. $\mathrm{BBs}$ are facing an urgent need for a consensus on the clinical and neuropathological diagnostic criteria that will make their specimens suitable for high-quality research. The benefits of this will be considerable, as improved understanding of neurological and psychiatric disorders will contribute significantly to the elucidation of their underlying disease mechanisms, and this has the potential to identify rational therapeutic targets.
\end{abstract}

Keywords: postmortem autopsy, ethical, legal and social issues, proteomics, neurological disorders, matrix-assisted laser desorption ionization-mass spectrometry

\section{Introduction}

Brain, tissue, and bio (BTB)-banks play a key role in the progression of neuroscience, enabling and sustaining both clinical and preclinical research. Brain banks (BBs) are globally spread, and exhibit a large diversity of approaches to all aspects of brain banking. This affects and influences the main fields of scientific research, with the supply of tissue samples for research showing a strong dependence on local ethical, legal, and social issues (ELSIs), as well as on the cultural and religious backgrounds of each country. BBs abide by specific protocols for tissue collection and cryopreservation, which can vary considerably, in order to facilitate a broad range of research approaches. A BB is essentially a prospective project for the collection of human central nervous system (CNS)-tissue specimens, with the underlying support of donor programs and national health systems.

The first special issue of a journal relating to the practicalities of brain banking was published in 1993 and edited by Cruz-Sánchez and Tolosa. ${ }^{1}$ This was followed by several papers considering the ethical aspects of brain banking within existing and new BBs, and the operational procedures developed at The Netherlands Brain Bank. ${ }^{2-10}$ In 2008, a special issue of Cell and Tissue Banking was dedicated to "How to run a brain bank". ${ }^{11,12}$
Correspondence: Rivka Ravid Brain Bank Consultants, Amsterdam, the Netherlands Tel/fax +3I 206475907

Email rivkagravid@gmail.com
Journal of Biorepository Science for Applied Medicine 20I4:2 17-27 17

Dovepress

http://dx.doi.org// 0.2147/BSAM.S4657| (c) (i) (5) 2014 Ravid and Park. This work is published by Dove Medical Press Limited, and licensed under Creative Commons Attribution - Non Commercial (unported, v3.0)

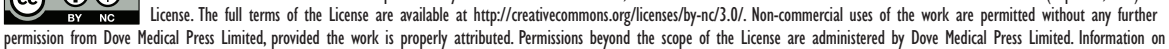
permission from Dove Medical Press Limited, provided the work is properly attributed. P
how to request permission may be found at: http://www.dovepress.com/permissions.php 
The current review provides an update on this rapidly developing field, describing some of the major advances and challenges, discussing the development of creative solutions, and considering the impact of modern research tools on current and future brain banking. The review describes the gold standards of brain banking and the specific features of BBs, reflecting the current state of the art in the daily practice of modern brain banking and the key methodological, managerial, and organizational procedures, standard operating procedures (SOPs) and guidelines for ELSIs. We also highlight the use of molecular biology, genetics, magnetic resonance imaging (MRI)-guided pathology, and proteomics as examples of creative solutions and efficient tools in neuroscience research. ${ }^{13-20}$ In addition to highlighting the classic pitfalls and lessons learnt from the past, we also offer perspectives on where the brain-banking field is likely to go in the future. ${ }^{11,13,21-23}$ We specify the potential value of good practice when collecting, banking, and studying highquality human CNS-tissue specimens for the advancement of medicine, science, and health care in our societies. The legislative and ethical frameworks needed to run BBs are still subject to debates that will determine the future continuity of research into neurological and psychiatric disorders.

The daily practices and procedures employed within BBs in Europe, Asia, the Americas, Australia, and New Zealand vary depending on differences in national legislative environments and scientific communities, and the interactions between these two. ${ }^{24-30}$ The efforts of the international BTB-bank networks to collaborate on the standardization of protocols and diagnostic criteria started in the 1990s, within the first European dementia group (EURAGE [European Research Group on Attitudes to Age]), and are ongoing. ${ }^{31-34}$ There are also parallel efforts to establish global and robust consensus criteria for the clinical and neuropathological diagnoses of neurodegenerative disorders. ${ }^{35-38}$

Although BBs rely on high-quality clinical and neuropathological support services, their activities are mainly directed toward research. This consideration allows us to discern BBs from neuropathological or clinic-based laboratories, where tissue handling and diagnostic services are directed to specific tests, with no necessity to conform to the prospective standardized protocols required for multidisciplinary research. A BB also facilitates the collection of control tissue, which could otherwise be difficult to obtain in a clinical service setting. The absence of current agreed international criteria for the collection and preservation of human autopsytissue specimens is one of the reasons the standardization of procedures and criteria is so important. ${ }^{39-41}$
Networking between European BBs can contribute to the coordination of local activities and outputs, and can also contribute on the international level by collaborating with BBs in Asia, the Americas, Australia, and New Zealand. This has the potential to produce a scientific output that will exceed the sum of its parts, by enabling the pooling of large numbers of research specimens, improving the available patient data, providing reliable statistical analysis of the results obtained, and expanding the range of sophisticated molecular biological techniques available for tissue analysis. It will also make more efficient use of the specific skills of each local BB, helping to improve the field overall and address some information gaps.

Global collaboration is necessary in order to pool knowledge and expertise in modern neurobiological techniques, in addition to providing more equal access to resources and material, which are certainly not evenly distributed between countries at the present time. These differences have arisen because of ethical issues, cultural and religious backgrounds, or socioeconomic differences, which can render brain banking and related research incredibly difficult. This global collaborative approach is the only feasible way to perform good-quality research that cannot be achieved at a national or regional level. European collaborative activities started with EURAGE and were followed by the establishment of the European Brain Bank Network and BrainNet Europe. These are also currently incorporated into the Biobanking and Biomolecular Resources Research Infrastructure network. Global collaboration aims to improve the compatibility of the diagnostic criteria, handling procedures, and dissection protocols, all of which facilitate the exchange of specimens between banks and researchers. BTB-bank networks are also used for the identification and validation of biomarkers for neurological and psychiatric disorders, both in vivo and at autopsy (Figure 1).

The recent explosive developments in preclinical and clinical research into human neurological and psychiatric disorders are partly attributable to progress and growth in the field of BTB banking. The gold standards of brain banking, outlined in Table S1 and the "Major issues of daily practice in brain banking" section of the Supplementary materials, relate to BB organization, the methodology used to recruit donors, the collection of specimens, the handling and storage of specimens, the SOPs, and the ELSIs. The specific issues involved in brain banking are described in the "Major issues of daily practice in brain banking" section; the guidelines for caution regarding financial "gain" and the supply of specimens to pharmaceutical 




Figure I A schematic overview of the brain, tissue, and bio (BTB)-banking flowchart for biomarker validation.

Note: The scheme illustrates that BTB banks act as a bridge liaising all stakeholders for identifying and validating central nervous system biomarkers both in vivo and at postmortem autopsy.

Abbreviation: CSF, cerebrospinal fluid.

companies and other commercial entities have been considered previously. ${ }^{42,43}$

The underlying pathologies and causes of most neurological and psychiatric disorders remain unknown, and current scientific research is focusing on their neurobiological features and neuropathological changes in the brains of affected patients. The BBs that collect specimens from autopsy-validated cases are fairly young; there is no one globally accepted standard protocol for tissue collection and handling, and there is an incomplete consensus on diagnostic criteria. In order to update their techniques, protocols, and diagnostic procedures continuously, BTB banks need to be in the immediate proximity of an academic center with a strong neuroscience tradition. The banks also need to establish an effective donor program and have ongoing collaborations with a large number of patients' associations, clinicians, hospitals, mental institutions, nursing homes, pathologists, undertakers, autopsy assistants, and scientists.

Quality control is one of the major issues in brain banking, and optimal procedures make the use of specimen $\mathrm{pH}$ a measure of agonal state. This guarantees the quality of the tissue specimens and messenger ribonucleic acid (RNA) prepared from them for scientific research. The $\mathrm{pH}$ of human specimens has been shown to be directly correlated with the agonal state, just prior to death: prolonged agonal state and ischemic brain damage influence brain tissue $\mathrm{pH}$; therefore, $\mathrm{pH}$ measurement in brain tissue is a good indicator of antemortem events in the brain. As antemortem events influence the biochemical quality of brain tissue, a 3-point scale was used to classify the agonal state of the patient. ${ }^{44}$ The categorization is as follows: 1) rapid death due to violent or natural causes, defined as the sudden, unexpected death of people who had apparently been reasonably healthy; the most frequent cause of death in this group is myocardial infarction; 2) intermediate death - this group consists of patients who were ill but whose deaths were unexpected; they could be classified as neither sudden deaths nor slow deaths; and 3) slow death, defined as a death after an illness with a prolonged terminal phase; typically, these patients died from cancers, cerebrovascular disease, or bronchopneumonia.

The traditionally recognized confounders that reduce tissue quality are agonal factors (eg, coma, hypoxia, hyperpyrexia at the time of death), and long postmortem delay (PMD). Another good parameter for tissue quality is RNA quality, as indicated by the RNA-integrity number, which is well correlated with tissue $\mathrm{pH}$. The $\mathrm{pH}$ of postmortem brain tissue is less dependent on factors associated with tissue handling and PMD, and more dependent on such factors as agonal state and ischemia prior to death. Therefore, $\mathrm{pH}$ may serve as a useful and easily applicable initial screening procedure in the assessment of postmortem brain tissue for research (Figure 2). ${ }^{4,44} 46$

All cases and controls should be matched for various antemortem and postmortem factors to allow each brain area dissected from a diseased patient to be matched with an identical area from a control patient. Important antemortem factors include age, sex, agonal state, date and place of death (to allow consideration of seasonal alterations), precise time of death (to allow consideration of circadian variation), and medication. Postmortem factors include postmortem delay, tissue fixation and storage time, and laterality. ${ }^{4-8}$ Reducing the variability of collected material has a range of advantages, as many patient-related factors introduce systematic errors. In addition, many neuroscientists working on Alzheimer's disease $(\mathrm{AD})$ require tissue specimens from patients who had other neurological disorders, in addition to nondemented controls, to analyze whether any differences observed are disease-specific (Table S2 and Figure 3).

The availability of postmortem material from patients with psychiatric disorders is still limited, while interest from 


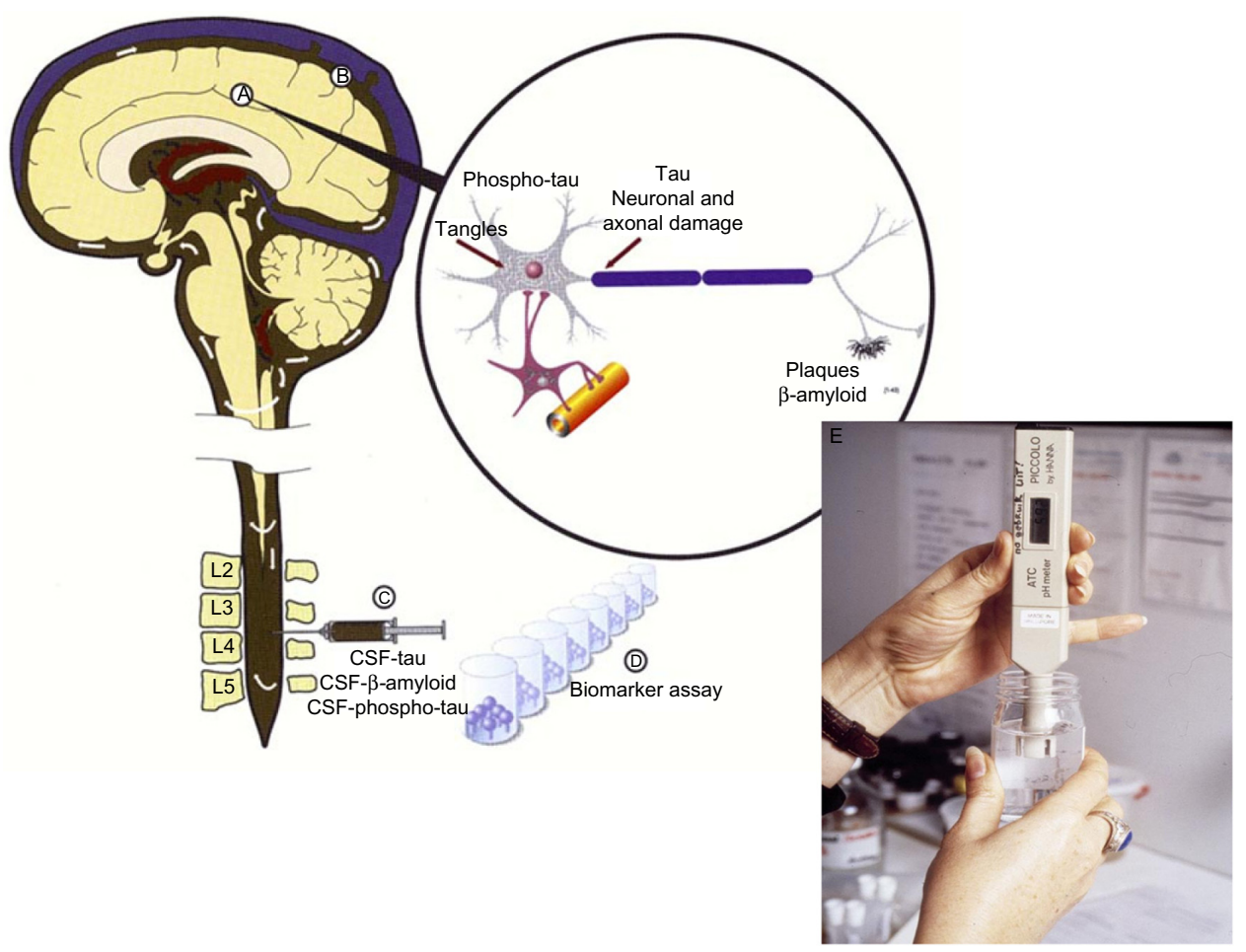

Figure 2 The use of cerebrospinal fluid (CSF) $\mathrm{pH}$ as a parameter for the agonal state of the brain.

Notes: $\mathrm{pH}$ measurement of brain tissue or CSF is a good indicator of pre-mortem events in the brain and serves as a reliable parameter for specimen quality for research. (A) Cerebral cortex; (B) arachnoids; (C) lumbar puncture; (D) biomarker assay of tau and amyloid; (E) pH measurement of CSF during rapid brain autopsy.

the international scientific community is growing. In order to provide a solution to this problem, BBs have developed close collaborations with institutions caring for patients with these conditions, to implement postmortem research programs for the most prevalent psychiatric disorders, such as depression, bipolar disorders, and schizophrenia. These programs may also provide opportunities for genetic research by providing simultaneous access to patients and their relatives.

Schizophrenia research in human subjects has progressed rapidly in the last decade, partly due to the development of

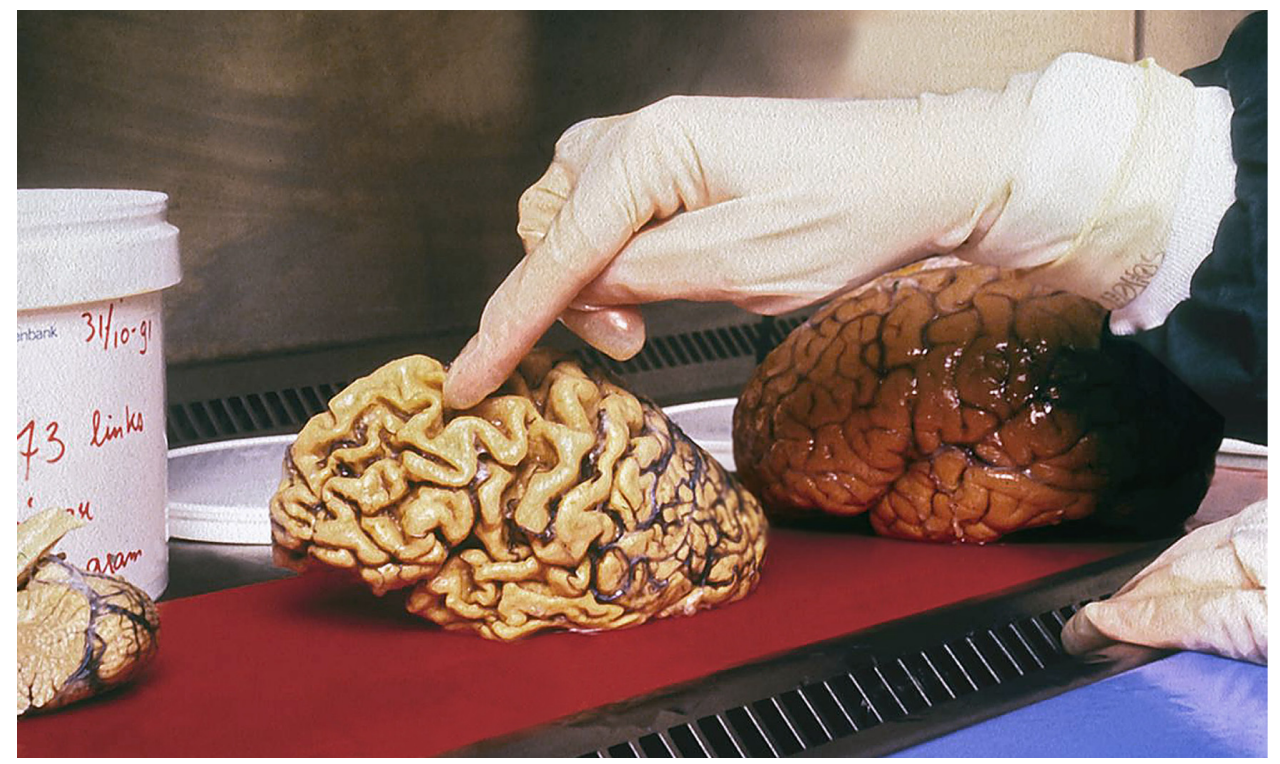

Figure 3 Matching in brain banking is mandatory, as the variation between control and disease is so pronounced.

Notes: Observe the differences between the brain on the right, from a deceased donor who did not have any neurological/psychiatric disorders, and the brain on the left, from a donor who died from Alzheimer's disease. 
techniques that enabled in vivo studies using computerized tomography and MRI; these have proved to be highly successful, noninvasive, fast techniques to investigate brain morphology. The lack of clear histopathological markers of disease, and the lack of consistent neuropathological findings, has contributed to a loss of interest in postmortem research in this area. ${ }^{24-30}$ It would be very advantageous to develop MRI-guided pathology in the near future, similar to the work carried out in individuals with multiple sclerosis (MS) (see MRI-guided dissection section), to enhance the postmortem data obtained at autopsy in individuals with psychiatric illnesses.

Several structural imaging studies have shown subtle changes in brain structure in schizophrenia, eg, enlargement of the ventricles and the cortical sulci, and smaller hippocampi. This implies a neurobiological substrate for this disease. Minor tissue abnormalities in limbic structures were also reported, and as limbic dysfunction may lead to a dissociation between cognitive activities and emotional reactions, these findings may be relevant to several aspects of the psychopathology of schizophrenia.

Tissue specimens collected by BBs worldwide have thus led to huge scientific benefits in the research of a range of neurological and psychiatric disorders. Many of these research studies have advanced understanding of the disease mechanisms, pathological hallmarks, and genetics of AD, ${ }^{47-50}$ frontotemporal dementia (FTD),${ }^{51-53}$ Parkinson's disease (PD), ${ }^{54-56}$ and MS. ${ }^{57-60}$ The development of creative new techniques in brain banking listed in the following sections has significantly contributed to research.

\section{Rapid-autopsy program}

With a very short postmortem delay ranging between 2-6 hours, rapid autopsies improve the quality of specimens and minimize their disintegration. The success of such programs results from the use of nurse clinicians who work closely with patients and their families to ensure a successful autopsy at the time of death and the maintenance of a 24/7 call schedule for nurses and neuropathology staff. The short PMD makes the obtained tissue samples suitable for a broad spectrum of techniques, including molecular biological techniques, as well as for neuronal slice cultures.

\section{Fresh dissection}

Fresh dissection of the brain has been developed in the last decade, based on precise anatomical guidelines that are important for the reproducibility of results. It also guarantees the freezing or fixing of tissue while intact for use in modern neurobiological techniques. This is a difficult regime to establish, requiring qualified staff at inconvenient times. Fresh dissection is necessary for the immediate use of fresh tissue, and is advantageous in increasing the range of morphological, neurochemical, immunocytochemical, and metabolic techniques that can be applied to rapidly frozen brain tissue free of freezing artifacts.

\section{MRI-guided dissection}

MRI-guided dissection has significantly extended the understanding of MS by sensitively depicting the dynamics of the disease process in vivo. In $2004,{ }^{60}$ an improved technique was developed to identify MS lesions showing active demyelination, which are of great relevance to the study of MS pathogenesis, but are rare in typical chronic MS-autopsy material. The yield of MS lesions identified in autopsy specimens can be increased by using MRI-guided tissue sampling, as a significant proportion of abnormalities detected by postmortem MRI are not macroscopically visible or palpable. Further histopathological examination has revealed that the majority of these MRI abnormalities represent either discrete areas of microglial activation with no demyelination (so-called preactive lesions) or active demyelinating MS lesions. The use of rapid autopsies, fresh dissection, and MRI of fresh brain slices and spinal cord prior to dissection has significantly improved the value of postmortem tissue in MS research, and this innovative technique has led to a wealth of information on gray-matter changes, apparently normal white matter, and the genetics of MS (Figure 4).

\section{Epidemiological studies}

Epidemiological studies and collaborations between clinicians, pathologists, and BBs have led to the discovery of familial disease cases and genetic mutations.

\section{Biomarkers}

The identification and validation of biomarkers in both in vivo samples and autopsy specimens has generated new insights into neurological disorders. Biomarkers identified in body tissues and fluids can be used in combination with imaging biomarkers to facilitate the development of new diagnostic tools.

\section{Proteomics}

Well-documented autopsy material has been used to analyze the human brain proteome in neurodegenerative diseases and in normal aging. ${ }^{61-64}$ Changes in the human brain proteome are of vital importance in the early stages of the 


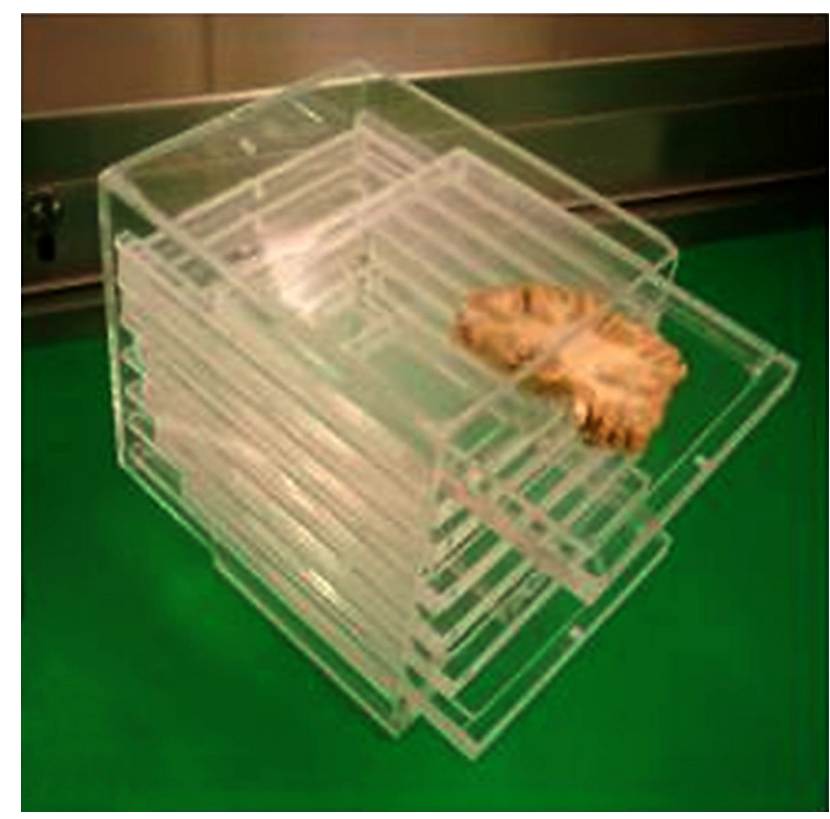

Figure 4 The "brain-slice holder" (mold).

Notes: The "brain-slice holder" (mold) is inserted into the magnetic resonanceimaging machine, and can hold up to seven coronal brain slices in one session. It fits into a standard magnetic resonance head coil, and following imaging, the $10 \mathrm{~mm}$ thick coronal brain sections are separated into two $5 \mathrm{~mm}$-thick specimens.

development of these diseases in the brain. The use of large collections of specimens, both frozen and formalin-fixed, paraffin-embedded tissue, in addition to blood, serum, and cerebrospinal fluid, has facilitated analysis of the membrane and soluble-fraction brain proteomes in neurological disorders. The use of island-clustering analysis ${ }^{19}$ following gel electrophoresis facilitates these comparisons between membrane and soluble protein fractions; this technique also enables identification of diagnostic biomarker proteins in neurological diseases and aging.

Longitudinal clinical data can also be combined with proteomic information to study clinicopathological correlates. During the 2011 Human Proteome Organization meeting, a decision was taken to launch the international, multidisciplinary Human Brain Proteome Atlas Project. The overarching goal of the project is to analyze the proteomes of distinctive areas within the healthy human brain during normal aging, and to compare these with the proteomes of the same areas in subjects with specific diseases, such as epilepsy, AD, and PD. This will be very helpful in optimizing techniques for analysis of the proteomic compositions of distinctive brain regions using robust, integrative bioinformatics. In combination with these new techniques to unravel the human brain proteome, BBs contribute their extensive experience of working with postmortem brain and body-fluid specimens, and their knowledge of neuroanatomy and neuropathology, creating a powerful new research tool for the investigation of molecular and biochemical aspects of the brain. ${ }^{18-23,34}$

Several proteins are present in the common pathological hallmarks of various neurological diseases, and these can be validated using proteomic tools. For example, the tau protein is present in neurofibrillary tangles, and these are used as hallmarks for AD and FTD; TAR deoxyribonucleic acid-binding protein 43 is present in FTD and amyotrophic lateral sclerosis; amyloid- $\beta$ is a peptide found in the hallmark lesions of $\mathrm{AD}$ and congophilic amyloid angiopathy; myelin basic protein is present in healthy myelin, and is also used as a hallmark for MS; and $\alpha$-synuclein is found in Lewy bodies and inclusions found in Lewy body disease and PD. This reflects the fact that many neurological disorders present mixed features, both clinically and neuropathologically.

The application of matrix-assisted laser desorption ionization-mass spectrometry (MALDI imaging) facilitates the detection of the earliest disease-specific proteomic changes in the brains of patients; this powerful methodology can be applied to a large array of neurological disorders, including PD, Lewy body disease, and AD. MALDI imaging is able to detect and measure minute levels and distributions of neuropeptides and proteins directly in tissue sections (Figure 5). ${ }^{20,61-64}$ Clinically, several neurological disorders are characterized by motor features and dementia. In the brains of affected individuals, peptide and protein patterns are complex, and new molecular tools, such as MALDI imaging, are needed to characterize these patterns and to identify specific proteins involved in neurodegeneration. Profiling MALDI imaging can be used to generate peptide and protein profiles of brain-tissue sections, and also enables the localization of peptides and proteins in much smaller areas. Combining

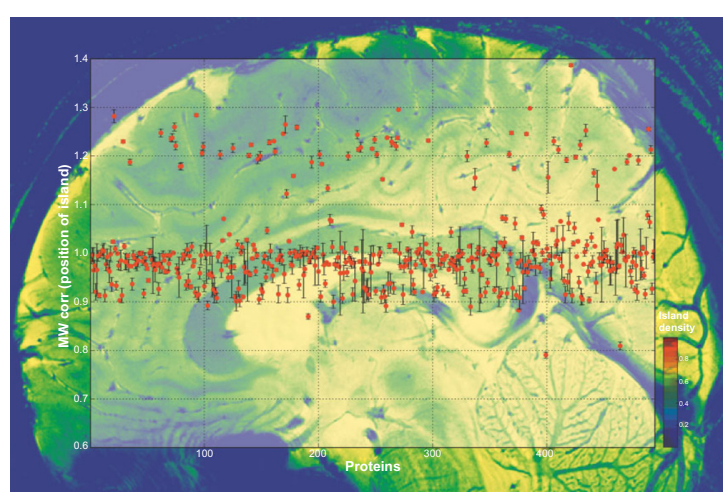

Figure 5 Protein identification in multiple separate bands of an I-D gel. Notes: Protein identification in multiple separate bands of an I-D gel, reflecting variation in the molecular weight caused by alternative splicing, endoproteolytic cleavage, or posttranslational modifications, such as glycosylation or ubiquitination. Protein identification was performed by quantifying the island distribution using the Iscore (quantitative measure of protein identification based on the protein island band distribution). 

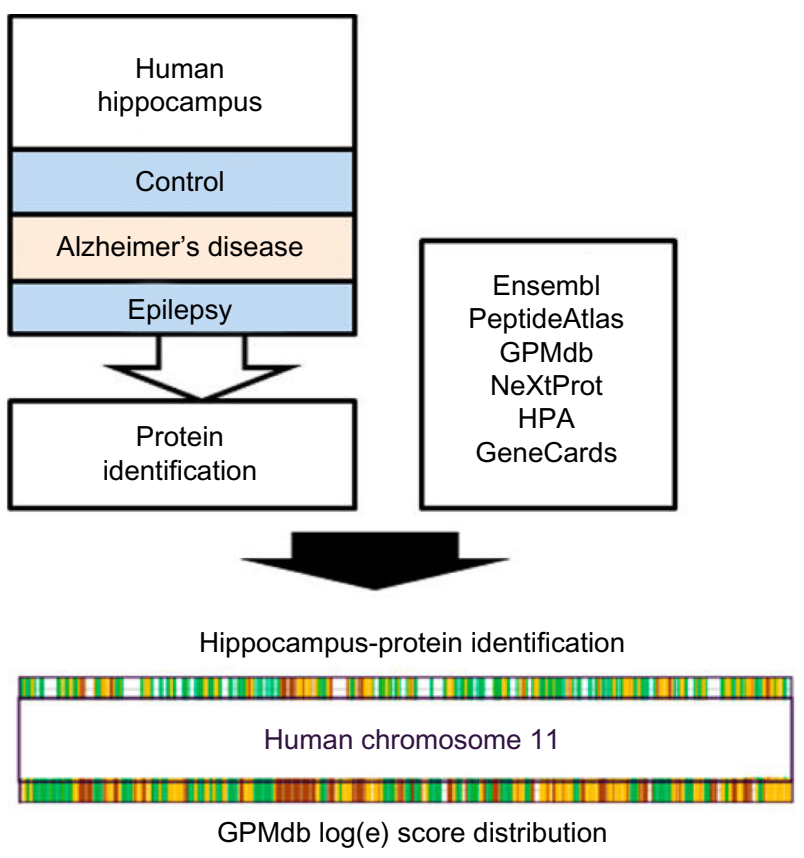

Figure 6 Flowchart of hippocampal proteomics using surgery and autopsy material. Notes: Protein samples were prepared using extensive off-gel fractionation from soluble and membrane fractions of control, epilepsy, and Alzheimer's tissue samples. The resulting peptides are separated by reversed-phase chromatography and identified by high-resolution mass spectrometry.

Abbreviations: GPMdb, Global Proteome Machine database; HPA, Human Proteome Atlas.

this mapping of a given protein at a high spatial resolution with markers of cellular components permits unambiguous determination of molecular entities at the subcellular level in the brain (Figure 6).

\section{Conclusion}

The use of the techniques in the previous sections can enable the identification of qualitative and quantitative proteomic differences, and use of the National Center for Biotechnology Information database can assist identification of cleaved proteins, or those with post-translational modifications, such as glycosylation or ubiquitination. Identification of these proteins and their modifications will simplify and facilitate the identification of cellular alterations associated with CNS diseases, and may result in the identification of novel therapeutic targets and diagnostics (Figure 6). ${ }^{61-64}$

With regard to the future, it is evident that numerous potential pitfalls remain to be addressed, especially when human brain tissue is studied using conventional neuroanatomical techniques. The global decline in autopsy rates is a worrying situation that makes well-organized and efficient BBs all the more vital. The search will continue for optimal approaches to overcoming obstacles to collaborative research and consensus SOPs. ${ }^{65,66}$ The scarcity of tissue from normal control subjects represents a major concern for BBs and researchers worldwide. The need for and importance of such controls cannot be overemphasized, as they are essential for scientists comparing disease states with normal tissue. In addition, cases with other neurological and psychiatric conditions may be studied within a "disease-control" group, to determine whether changes observed are specific to the particular disease of interest or present in other CNS conditions. A complete BB should thus ideally include a variety of clinically and pathologically well-documented cases with a range of neurological and psychiatric conditions.

The present review reflects current issues in modern global brain banking, highlighting the great potential and numerous pitfalls in its daily practice and describing our use of creative solutions to improve the impact of banked specimens. The use of proteomics as a unique brain-research tool serves as an example of the broad spectrum of ongoing technical and methodological developments and challenges that need to be addressed for future high-impact brain banking.

\section{Disclosure}

The authors report no conflicts of interest in this work.

\section{References}

1. Cruz-Sánchez FF, Tolosa E. The need of a consensus for brain banking. J Neural Transm Suppl. 1993;39:1-4.

2. Cruz-Sánchez FF, Mordini E, Ravid R. Ethical aspects to be considered in brain banking. Ann Ist Super Sanita. 1997;33(4):477-482.

3. Cruz-Sánchez FF, Ravid R, Cuzner ML. The European Brain Bank Network (EBBN) and the need of standardized neuropathological criteria for brain tissue cataloguing. In: Cruz-Sánchez FF, Cuzner ML, Ravid R, editors. Neuropathological Diagnostic Criteria for Brain Banking (Biomedical and Health Research). Amsterdam: IOS; 1995:1-3.

4. Ravid R, van Zwieten EJ, Swaab DF. Brain banking and the human hypothalamus - factors to match for, pitfalls and potentials. Prog Brain Res. 1992;93:83-95.

5. Ravid R, Winblad B. Brain banking in Alzheimer's disease: factors to match for, pitfalls and potentials. In: Corain B, Iqbal K, Nicolini M, Winblad B, Wisniewsky H, Zatta P, editors. Alzheimer's Disease: Advances in Clinical and Basic Research. New York: John Wiley \& Sons; 1993:213-218.

6. Ravid R, Swaab DF. The Netherlands Brain Bank - a clinicopathological link in aging and dementia research. J Neural Transm Suppl. 1993;39:143-153.

7. Ravid R, Swaab DF. Brain banking in Alzheimer's disease: pitfalls and potentials. Neuropathol Appl Neurobiol. 1995;21 Suppl 1:18-19.

8. Ravid R, Swaab DF, van Zwieten EJ, Salehi A. Controls are what makes a brain bank go round. In: Cruz-Sánchez FF, Ravid R, Cuzner ML, editors. Neuropathological Diagnostic Criteria for Brain Banking. Amsterdam: IOS; 1995:4-13.

9. Grinberg LT, Ferretti RE, Farfel JM, et al. Brain bank of the Brazilian aging brain study group - a milestone reached and more than 1,600 collected brains. Cell Tissue Bank. 2007;8(2):151-162.

10. Ferrer I, Armstrong J, Capellari S, et al. Effects of formalin fixation, paraffin embedding, and time of storage on DNA preservation in brain tissue: a BrainNet Europe study. Brain Pathol. 2007;17(3): 297-303. 
11. Ravid R, Grinberg L. How to run a brain bank - revisited. Cell Tissue Bank. 2008;9(3):149-150.

12. Ravid R. Standard operating procedures, ethical and legal regulations in BTB (brain/tissue/bio) banking: what is still missing? Cell Tissue Bank. 2008;9(3):151-167.

13. Ravid R. Biobanks for biomarkers in neurological disorders: the Da Vinci bridge for optimal clinico-pathological connection. J Neurol Sci. 2009;283(1-2):119-126.

14. Nielsen AS, Ravid R, Kamphorst W, Jørgensen OS. Apoliprotein E $\varepsilon 4$ in an autopsy series of various dementing disorders. J Alzheimers Dis. 2003;5(2):119-125.

15. Enard W, Khaitovich P, Klose J, et al. Intra- and interspecific variation in primate gene expression patterns. Science. 2002;296(5566):340-343.

16. Bö L, Geurts JJ, Ravid R, Barkhof F. Magnetic resonance imaging as a tool to examine the neuropathology of multiple sclerosis. Neuropathol Appl Neurobiol. 2004;30(2):106-117.

17. Ferrer I, Santpere G, Arzberger T, et al. Brain protein preservation largely depends on the postmortem storage temperature: implications for study of proteins in human neurologic diseases and management of brain banks: a BrainNet Europe Study. J Neuropathol Exp Neurol. 2007;66(1):35-46.

18. Park YM, Kim JY, Kwon KH, et al. Profiling human brain proteome by multi-dimensional separations coupled with MS. Proteomics. 2006;6(18):4978-4986.

19. Kwon KH, Park GW, Kim JY, et al. Island clustering analysis for the comparison of the membrane and the soluble protein fractions of human brain proteome. Proteomics. 2008;8(6):1149-1161.

20. Wisztorski M, Croix D, Macagno E, Fournier I, Salzet M. Molecular MALDI imaging: an emerging technology for neuroscience studies. Dev Neurobiol. 2008;68(6):845-858.

21. Ravid R, Ferrer I. Brain banks as a key part of biochemical and molecular studies on cerebral cortex involvement in Parkinson's disease. FEBS J. 2012;279(7):1167-1176.

22. Alberio T, Fasano M. Proteomics in Parkinson's disease: an unbiased approach towards peripheral biomarkers and new therapies. J Biotechnol. 2010;156(4):325-337.

23. Ravid R, Fasano M. The importance of harmonizing and standardizing CNS biomarkers of neurodegeneration. Future Neurol. 2012;7(6):663-666.

24. Ravid R. Methodological considerations of the establishment of a brain bank for psychiatric research: the Amsterdam and European experience. In: Agam G, Belmaker RH, Everall I, editors. The Postmortem Brain in Psychiatric Research. Norwell (MA): Kluwer Academic; 2002:8-13.

25. Matsumoto I, Niwa SI, Ravid R. Psychiatric brain banks: situation in Europe and Asia. In: Agam G, Belmaker RH, Everall I, editors. The Postmortem Brain in Psychiatric Research. Norwell (MA): Kluwer Academic; 2002:3-10.

26. Dean B, Boer S, Gibbons A, Money T, Scarr E. Recent advances in postmortem pathology and neurochemistry in schizophrenia. Curr Opin Psychiatry. 2009;22(2):154-160.

27. Ravid $\mathrm{R}$. The pitfalls and practicalities in collecting and banking human brain tissues for research on psychiatric and neurological disorders. Psychiatry Clin Neurosci. 2007;61:S19-S23.

28. Schmitt A, Bauer M, Heinsen H, et al. How a neuropsychiatric brain bank should be run: a consensus paper of Brainnet Europe II. J Neural Transm Suppl. 2007;114:527-537.

29. Deep-Soboslay A, Benes FM, Haroutunian V, Ellis JK, Kleinman JE, Hyde TM. Psychiatric brain banking: three perspectives on current trends and future directions. Biol Psychiatry. 2011;69(2):104-112.

30. Ravid R, Ikemoto K. Pitfalls and practicalities in collecting and banking human brain tissues for research on psychiatric and neulogical [sic] disorders. Fukushima J Med Sci. 2012;58(1):82-87.

31. Duyckaerts C, Delaère $P$, Hauw JJ, et al. Rating of the lesions in senile dementia of the Alzheimer type: concordance between laboratories. A European multicenter study under the auspices of EURAGE. J Neurol Sci. 1990;97:295-323.
32. Alafuzoff I, Pikkarainen M, Al-Sarraj S, et al. Interlaboratory comparison of assessments of Alzheimer disease-related lesions: a study of the BrainNet Europe consortium. J Neuropathol Exp Neurol. 2006;65(8):740-757.

33. Beach TG, Sue LI, Walker DG, et al. The Sun Health Research Institute Brain Donation Program: description and experience, 1987-2007. Cell Tissue Bank. 2008;9(3):229-245.

34. Ferrer I, Martinez A, Boluda S, Parchi P, Barrachina M. Brain banks: benefits, limitations and cautions concerning the use of post-mortem brain tissue for molecular studies. Cell Tissue Bank. 2008;9(3): 181-194.

35. McKhann GM, Knopman DS, Chertkow H, et al. The diagnosis of dementia due to Alzheimer's disease: recommendations from the National Institute on Aging-Alzheimer's Association workgroups on diagnostic guidelines for Alzheimer's disease. Alzheimers Dement. 2011;7(3):263-269.

36. Braak H, Ghebremedhin E, Rüb U, Bratzke H, del Tredici K. Stages in the development of Parkinson's disease-related pathology. Cell Tissue Res. 2004;318(1):121-134.

37. Dickson DW. Required techniques and useful molecular markers in the neuropathologic diagnoses of neurodegenerative diseases. Acta Neuropathol. 2005;109(1):14-24.

38. Dickson DW, Braak H, Duda JE, et al. Neuropathological assessment of Parkinson's disease: refining the diagnostic criteria. Lancet Neurol. 2009;8(12):1150-1157.

39. Waldvogel HJ, Bullock JY, Synek BJ, Curtis MA, van Roon-Mom WM, Faull RL. The collection and processing of human brain tissue for research. Cell Tissue Bank. 2008;9(3):169-179.

40. Vonsattel JP, Del Amaya MP, Keller CE. Twenty-first century brain banking. Processing brains for research: the Columbia University methods. Acta Neuropathol. 2008;115(5):509-532.

41. Keller CE, Amaya MP, Cortes EP, Mancevska K, Vonsattel JP. Electronic tracking of human brain samples for research. Cell Tissue Bank. 2008;9(3):217-227.

42. Womack C. Ethical issues relating to supply of human tissue to the commercial biomedical sector. Cell Tissue Bank. 2002;3(3):203-209.

43. Womack C. Supply and use of human tissue for research purpose: survey of BATB affiliated tissue banks. Cell Tissue Bank. 2006;7(3): 207-209.

44. Hardy JA, Wester P, Winblad B, Gezelius C, Bring G, Eriksson A. The patients dying after long terminal phase have acidotic brains: implications for biochemical measurements on autopsy tissue. J Neural Transm. 1985;61(3-4):253-264.

45. Kingsbury AE, Foster OJF, Nisbet AP, et al. Tissue $\mathrm{pH}$ as an indicator of mRNA preservation in human post-mortem brain. Brain Res Mol Brain Res. 1995;28(2):311-318.

46. Tomita H, Vawter MP, Walsh DM, Evans SJ, Choudary PV, Li J. Effect of agonal and postmortem factors on gene expression profile: quality control in microarray analyses of postmortem human brain. Biol Psychiatry. 2004;55(4):346-352.

47. Reiman EM, Webster JA, Myers AJ, et al. GAB2 alleles modify Alzheimer's risk in APOE $\varepsilon 4$ carriers. Neuron. 2007;54(5):713-720.

48. Webster JA, Myers AJ, Pearson JV, et al. Sorl1 as an Alzheimer's disease predisposition gene? Neurodegen Dis. 2008;5(2):60-64.

49. Quinn JG, Coulson DT, Brockbank S, et al. $\alpha$-Synuclein mRNA and soluble $\alpha$-synuclein protein levels in post-mortem brain from patients with Parkinson's disease, dementia with Lewy bodies, and Alzheimer's disease. Brain Res. 2012;1459:71-80.

50. Rosso SM, Kaat LD, Baks T, et al. Frontotemporal dementia in The Netherlands: patient characteristics and prevalence estimates from a population-based study. Brain. 2003;126(Pt 9):2016-2022.

51. van Herpen E, Rosso SM, Severijnen LA, et al. Variable phenotypic expression and extensive tau pathology in two families with the novel tau mutation L315R. Ann Neurol. 2003;54(5):573-581.

52. van Swieten JC, Bronner IF, Azmani A, et al. The DeltaK280 mutation in MAP tau favors exon 10 skipping in vivo. J Neuropathol Exp Neurol. 2007;66(1):17-25. 
53. Bronner IF, Bochdanovits Z, Rizzu P, et al. Comprehensive mRNA expression profiling distinguishes tauopathies and identifies shared molecular pathways. PLoS One. 2009;4(8):e6826.

54. Rizzu P, Hinkle DA, Zhukareva V, et al. DJ-1 colocalizes with tau inclusions: a link between parkinsonism and dementia. Ann Neurol. 2004;55(1):113-118.

55. Grünblatt E, Zander N, Bartl J, et al. Comparison analysis of gene expression patterns between sporadic Alzheimer's and Parkinson's disease. J Alzheimers Dis. 2007;12(4):291-311.

56. Natale M, Bonino D, Consoli P, et al. A meta-analysis of twodimensional electrophoresis pattern of the Parkinson's disease related protein DJ-1. Bioinformatics. 2010;26(7):946-952.

57. Nijeholt GJ, Bergers E, Kamphorst W, et al. Post-mortem high-resolution MRI of the spinal cord in multiple sclerosis: a correlative study with conventional MRI, histopathology and clinical phenotype. Brain. 2001;124(Pt 1):154-166.

58. van Veen T, Nielsen J, Berkhof J, et al. CCL5 and CCR5 genotypes modify clinical, radiological and pathological features of multiple sclerosis. J Neuroimmunol. 2007;190(1-2):157-164.

59. Van Waesberghe JHTM, Kamphorst W, De Groot CJ, et al. Axonal loss in multiple sclerosis lesions: magnetic resonance insights into substrates of disability. Ann Neurol. 1999;46(5): 747-754.
60. Bot JC, Blezer EL, Kamphorst W, et al. The spinal cord in multiple sclerosis: relationship of high-spatial-resolution quantitative MR imaging findings to histopathologic results. Radiology. 2004;233(2): $531-540$.

61. Kwon KH, Kim JY, Kim SY, et al. Chromosome 11-centric human proteome analysis of human brain hippocampus tissue. J Proteome Res. 2013;12(1):97-105.

62. Lemaire R, Desmons A, Tabet JC, Day R, Salzet M, Fournier I. Direct analysis and MALDI imaging of formalin-fixed, paraffin-embedded tissue sections. J Proteome Res. 2007;6(4):1295-1305.

63. Gröttrup B, Marcus K, Grinberg LT, Lee SK, Meyer HE, Park YM. Creating a human brain proteome atlas - 14th HUPO BPP workshop, September 20-21, 2010, Sydney, Australia. Proteomics. 2011;11(16): 3269-3272.

64. Hamacher M, Gröttrup B, Eisenacher M, et al. Inter-lab proteomics: data mining in collaborative projects on the basis of the HUPO brain proteome project's pilot studies. Methods Mol Biol. 2011;696:235-246.

65. Royal College of Pathologists of Australasia Autopsy Working Party. The decline of the hospital autopsy: a safety and quality issue for healthcare in Australia. Med J Aust. 2004;180(6):281-285.

66. Watson PH, Ravid R, Eng CB, Litton JE, Vaught J, Matusan A. What are the main roadblocks to transnational biobank collaboration, and how can we overcome them? Biopreserv Biobank. 2011;9(3):213-216. 


\section{Supplementary materials \\ Major issues of daily practice in brain banking}

\section{Tissue procurement}

Procurement includes all regulations related to the donor program. Written consent from the donor and/or next-ofkin is mandatory for use of specimens for research. Respect for the dignity of human remains is considered at all times. All staff working with human remains are properly trained and qualified.

\section{Tissue management}

Tissue management includes factors related to the collection, handling, and preservation of tissues and safety regulations. All human specimens should be regarded as potentially biohazardous, and should be handled accordingly by appropriately trained personnel. Specific precautions should be taken against known hazards and general precautions against unknown hazards. All those potentially exposed to human

Table SI Seven gold standards in brain banking

\begin{tabular}{ll}
\hline I. Donor system & Individual BBs have a local donor system and a \\
& program to recruit donors. \\
Consent is obtained for the use of specimens \\
for scientific research and access to the medical \\
records. \\
In many cases, consent should also be granted \\
for genetic testing. Donor systems successfully \\
recruit donors with neurological and psychiatric \\
disorders, as well as controls.
\end{tabular}

\section{Rapid autopsy system}

3. Protocols

4. Diagnostic criteria

5. Quality control

6. Guidelines for ELSIs
Short postmortem delay and a fresh dissection are prerequisites for an increasing range of modern neuroscience techniques and successful brain banking.

Compatible protocols are used for tissue procurement, management, preparation, and storage for diagnostics and scientific research. Each bank abides by internationally acceptable SOPs.

The BB abides by clinical and neuropathological diagnostic criteria. The medical records should be screened for all available clinical and genetic data of the donors.

Quality control of the disseminated samples ( $\mathrm{pH} /$ agonal state).

BBs abide by internationally accepted guidelines for the ethical and legal aspects to conform to the local medicolegal system. BBs should be well aware of the international discussions with respect to ownership of specimens and use for research, coauthorship in publications, remuneration, and BRIF.

7. Safety measures Monitoring proper safety procedures.

Abbreviations: BBs, brain banks; SOPs, standard operating procedures; ELSls, ethical, legal, and social issues; BRIF, bioresource research impact factor.
Table S2 Matching factors in tissue banking

\begin{tabular}{ll}
\hline Antemortem & Postmortem \\
\hline - Age & - Postmortem delay \\
- Sex & - Organ weight \\
- Clinical diagnosis & - CSF/brain pH \\
- Agonal state & - Cause of death \\
- Medication & - Clock time of death \\
- Circadian variation & - Date of death \\
- Seasonal variation & - Death to refrigeration \\
- Lateralization & - Freezing/fixation \\
- Family history/genetic load & - Storage time \\
\hline
\end{tabular}

Abbreviation: CSF, cerebrospinal fluid.

brain tissues and fluids should be vaccinated against the hepatitis B virus and be regularly checked for levels of immunity. All disposable equipment used in conjunction with human brain tissues and fluids should be sterilized according to a recommended procedure before transport for incineration.

\section{Tissue dissemination}

Tissue dissemination involves factors related to supplying samples of high scientific quality and properly matched for specific projects. Users of CNS samples should undergo a process of accreditation, to ensure that a minimum set of criteria is fulfilled. These criteria include scientific peer review, ethical credibility, proper training, suitable facilities for safe handling and disposal of human tissues, and confidentiality. Whenever possible, this accreditation should be performed by an appropriately qualified and independent expert group. As the legislation and documentation concerning shipment of human-autopsy specimens varies between countries, the information regarding regulations of packing and national and international transport of human brain tissues and fluids should be made available to all parties involved in BB activities for research. All clinical documentation and information concerning specimens should be made available to users as quickly as possible. It is also advisable to incorporate research results of end users back to the database of the BB.

\section{Confidentiality}

The anonymity of specimens and patient records must be protected at all times. Samples supplied for research should be coded by the BB, and a tracking system restricted to local BBs must be established to guarantee the anonymity of the donor and enable data protection and sharing. Research using human tissues can bring new information about the donor that is also relevant to their family. This option should play an important role in ethical conduct and the return of results 
should be done by a clinical genetics department and not via the $\mathrm{BB}$.

\section{Financial "gain"}

It is highly important to establish BTB banks as nonprofit sources of human tissues for scientific research. The banks act as custodians of specimens that must not be commercially handled. On the other hand, it is extremely important to have reasonable coverage for the costs involved in procurement, handling, and transport (cost recovery). BTB banks are expensive organizations: annual running costs vary from $€ 10,000$ per brain collected in Europe to $\$ 15,000$ in the US and Asia. One possible solution to handle this issue is to incorporate the costs of obtaining specimens for research into the budget and grant application of the end users. This will include an estimate of expenses related to handling and management of specimens, as well as the costs involved in the acquisition and/or preservation of the specimens. The various professionals who are involved in obtaining, handling, and diagnosing the tissues have the right to be reimbursed for their services. It must be made clear in writing to all users that any possible payments are made only to cover the costs of the bank, which is forbidden to make any financial profit.

\section{Genetic testing}

The tremendous advances in genetic research in the past 10 years raise serious ethical problems and complexities; there is often conflicting interest in the need for knowledge and information, and the use and implications of this information for the people involved. Links found between certain genes and neurological diseases create a heavy burden on physicians, health care workers, and brain bankers who test for these genetic factors, as they are essential for the diagnostics and scientific interpretation of the results obtained on postmortem human brain tissues and fluids. This knowledge poses many difficult questions to concerned or afflicted individuals.

The rapid linkage between genes and diseases will have many future implications on international legal and ethical systems. It would be advisable to have a consensus between banks on this sensitive issue, as some of the genetic testing is done by collaboration between experts in different countries worldwide.

In applying for local ethics approval, care must be taken to include permission not only for diagnostic purposes but also for the use of tissue in research projects and for shipment of tissues to other labs. Permission must also include the use of (anonymous) clinical data and deoxyribonucleic acid for research purposes.
Journal of Biorepository Science for Applied Medicine

\section{Publish your work in this journal}

Journal of Biorepository Science for Applied Medicine is an international, peer-reviewed, open access journal that focuses on new developments and advances in the emerging and evolving field of biorepository science. This includes biospecimen procurement, processing, preservation, and banking for application to applied medicine. The Journal invites submission of manuscripts which address these aspects in addition to system logic, clinical throughput and ethical issues pertaining to application of biorepositories

\section{Dovepress}

and their affects on clinical medicine. The journal is characterized by the rapid reporting of reviews, original research, methodologies, technologies and analytics in this subject area. The manuscript management system is completely online and includes a very quick and fair peer-review system, which is all easy to use. Visit http://www.dovepress. com/testimonials.php to read real quotes from published authors. 